\title{
Surface Feature Extraction on the Basis of Object-oriented Remote Sensing Classification Methods in Manas River Basin
}

\author{
http://dx.doi.org/10.3991/ijoe.v10i6.4021 \\ Wang Ling, Su Jian-an, Guo Peng, Liu Lin \\ Geography Department of Shihezi University, Shihezi 832000, China;
}

\begin{abstract}
Remote-sensing (RS) images were extracted by using object-oriented remote sensing classification methods. This study combines RS and Geographic Information System to conduct multilevel segmentation and classify of the remote sensing image of Manas watershed. The e-Cognition system was selected to define the knowledge base following the classification system. The results show that the overall nicety of grading can reach $97.37 \%$ and that the Kappa coefficient is 0.9706 . These results show that land use can be described and extracted by using high spatial resolution remote-sensing images.
\end{abstract}

Index Terms-Object-oriented, Multi-level segmentation, Land use, e-Cognition, RS technology

\section{INTRODUCTION}

Changes in land use have caused global changes in recent years. Hence, obtaining accurate and updated land use information is important. The traditional sorting technique includes supervised classification and nonsupervised classification, which are based on the spectral information of the remote sensing (RS) system. The division criterion is the brightness characteristic of the pixel. Some other methods (e.g., vague and neural network classification methods) merely establish a classification scheme on the basis of pixel scale [1-2].

Two common RS phenomena are similar deciduous tree species with different spectral values and different deciduous tree species with the same spectral values. These phenomena may give rise to errors and reduce classification accuracy [3-4]. Therefore, the use of the traditional pixel-based RS classification method to extract land use information cannot satisfy the actual demand. This study uses the e-Cognition system to extract the land use information in Manas River Basin. This research provides a basis for reasonable exploitation and utilization.

\section{RESEARCH AREA}

Manas River Basin (Longitude $85^{\circ} 00^{\prime}-86^{\circ} 30^{\prime}$, north latitude $43^{\circ} 30^{\prime}-45^{\circ} 40^{\prime}$ ) is located in the northern foot of Tianshan Mountain, Xinjiang, China. The terrain of this drainage basin is high in the south but low in the north. The geomorphic types within the basin are high mountains with snow, subalpine with upper glacial, middle mountains with water, low hills, alluvial plains, lacustrine plains, and deserts. The highest elevation of the south mountain can reach $5289 \mathrm{~m}$, whereas the lowest elevation is $246 \mathrm{~m}$ in Manas Lake. The basin is located in both the continents of Europe and Asia. The spatial and temporal distributions of the precipitation within the basin exhibit significant disparity. The administrative divisions include Manaxin County, Shawan County, and Shi He-zi reclamation area. The total area of Manas River Basin is 26500 $\mathrm{km} 2$. The research area includes Taxi, Manas, Ning, Gold, South, and Bayin Rivers. The largest river in the basin is Manas River, the river length of which can reach $324 \mathrm{~km}$ [5]. From the upstream to the downstream area of Manas River, the degree of salinity decreases gradually, and the soil salinity constitution gradually shifts from sulfate to chloride salt. Thus, studies on the land use change in this basin are significant.

\section{DATASETS AND MeTHODS}

The RS data (TM image) used in this research (from August 2010 to September 2010) were obtained from the data center of Shihezi University. The data have a resolution ratio of $30 \mathrm{~m} \times 30 \mathrm{~m}$. All data were projected onto WGS 1984 UTM ZONE 45N. To obtain enhanced results, the $\mathrm{RS}$ images underwent several processes, including tailoring, splicing, and correction.

The TM satellite image has three wavebands with different functions, as shown in Table 1.

TABLE I.

MAIN FUNCTION AND THE BAND NAMES OF TM IMAGE

\begin{tabular}{cll}
\hline Feature & Band name and range $(\boldsymbol{\mu m})$ & Main function \\
\hline $\boldsymbol{T M 1}$ & Blue waveband $(0.45-0.52)$ & Used to distinguish soil, vegetation and artificial objects. \\
\hline $\boldsymbol{T M 2}$ & Green waveband $(0.52-0.60)$ & Used to detect the reflectivity of the plants and reflect the feature of the ground water \\
\hline $\boldsymbol{T M 3}$ & Red waveband $(0.62-0.69)$ & Used to measure the pigment of green plants and distinguish the artificial objects \\
\hline $\boldsymbol{T M 4}$ & Near-infrared waveband $(0.76-0.90)$ & Used to determine the biomass of the crop. \\
\hline $\boldsymbol{T M 5}$ & Middle-infrared waveband(1.55-1.75) & Used to detect the water content and the soil moisture \\
\hline $\boldsymbol{T M 6}$ & Infrared waveband(1.04-1.25) & Used for rock identification \\
\hline $\boldsymbol{T M 7}$ & Middle-infrared waveband(2.08-2.35) & Used to monitor forest fires and distinguish artificial objects \\
\hline
\end{tabular}


We collected other data for this research. These data include the land-use type and DEM data of Manas River, as well as the slope information within the basin. In addition, the Google Earth application was selected to analyze the surface features of the research area.

\section{ClassificATION USING OBJECT-ORIENTED AND MULTILAYER SPLITTING METHODS}

\section{A. Establishing a class hierarchy}

The surface features can be split step-by step by using the e-Cognition system. As a result of masking, the nicety of grading results may be enhanced [6]. The types of the surface features and the class hierarchy results are shown in Figure 2.

The layer dispersing methods were applied in all sorting processes. The large surface features (vegetation and nonvegetation) were extracted in level 1 , whereas the smaller surface features (e.g., settlement places, rivers, grasslands, tillage, forestry, bare soil, bare rocks, saline-alkali soil, ice, and snow ) were extracted in level 2. For convenient high-level analysis, the TM image adopted the same classification (See Table II).

\section{TABLE II.}

GRADATION CLASSIFICATION INFORMATION

\begin{tabular}{cl}
\hline Layer & Surface features \\
\hline \multirow{2}{*}{ Level 1 } & Vegetation \\
& Non-vegetation \\
& Forestry \\
& Grass land \\
Level 2 & Wet land \\
& Settlement place, Industrial estate, Rivers \\
& Bare soil, Bare rock, Saline-alkali soil and ice \\
\hline
\end{tabular}

\section{B. Segmentation of the remote sensing image}

Segmentation splits the overall image into different objects that correspond to the original object [7].

The standards of RS segmentation are as follows: 1) the mean heterogeneity of the image object should be reduced to the minimum value; 2 ) the average of the heterogeneity in pixels should be minimized, and the heterogeneity of the image to which the pixel belongs should be assigned to each pixel [8], and 3) image segmentation should be based on the spectral and geometric features of the TM image. Smaller images will gradually merge into a larger image to form a polygon with similar dimensions.

The selection of segmentation scale is very important because such scale will directly determine classification accuracy. For a given surface feature, a suitable scale value is the case in which segmented polygons can show the boundary clearly.

Several objects can be used to express this surface feature [9]. The split dimension determined the maximum heterogeneity of the TM image. If the split dimension is large, the surface detail would be ignored during the segmentation process, which may give rise to only a small number of polygons. By contrast, if the split dimensions are small, the details of the surface features will be emphasized, and the number of polygons will increase. The area of the polygons will also increase accordingly.

The e-Cognition system provides two homogeneity stands (color and shape). Color is the spectral signature of the TM image. During segmentation, the spectral signature is important because the main information included in the TM image is spectral data. Thus, the weight of the spectral data should be less than 0.1 in this research. The sum of the color and shape factors is equal to 1 . The shape features include both smoothness and compactness. Smoothness refers to the smoothness extent, whereas compactness refers to the extent of assembly between images. In the split process, the e-Cognition system considers not only the spectral information but also the shape factor of the surface feature.

We defined the relationship between the split process and the weighted value, that is, the weight of the layer will increase if the layer information is increased during the split process [10-11].

This study used the e-Cognition system to process the TM image into different dimensions, which are 600 and 15. The weights of color and shape respectively account for 0.7 and 0.3 of the homogeneity standard. The compactness and the smoothness values are both 0.5 . Specific parameter settings are shown in Table III, and the split effects are shown in Figure 3.

Figures 1(a) and 1(b) show that the split dimension of 600 will form a large but few polygons. Meanwhile, the split dimension of 15 will form small polygon, with similar object and ground boundaries.

\section{Image classification}

The reference rule set (RefranceRuleset_V1027.dcp) was used to distinguish the surface feature information [12]. We selected the typical characteristics of the research area on the basis of the extracted surface feature information. The classification standards of the TM image were finally determined by repeated experiments.

\section{INFORMATION EXTRACTION}

\section{A. Vegetation and non-vegetation extraction}

The Normalized Difference Vegetation Index (NDVI) of the vegetation was used to distinguish between vegetation and non-vegetation forms. The reason for selecting the NDVI as a distinguishing factor is that the glow waveband is easily absorbed by vegetation. We conducted the experiment several times and considered surfaces with NDVI value greater than 0.11 as vegetation.

\section{B. Snow and river extraction}

In level 2 , to mitigate disturbance by ice and snow, we first used the Normalized-Difference Snow Index (NDSI) to extract the cryoconite cover. We considered the features of the research area and defined the NDSI value of the coverage area as 0.4 .

TABLE III.

PARAMETER SETTINGS OF THE MULTI-RESOLUTION SEGMENTATION

\begin{tabular}{cccccc}
\hline Scale parameter & Shape & Color & Compactness & Smoothness & Layer weights \\
\hline 600 & 0.3 & 0.7 & 0.5 & 0.5 & $0,1,2,2,1,1,0$ \\
15 & 0.3 & 0.7 & 0.5 & $0,1,1,1,1,1,0$ \\
\hline
\end{tabular}




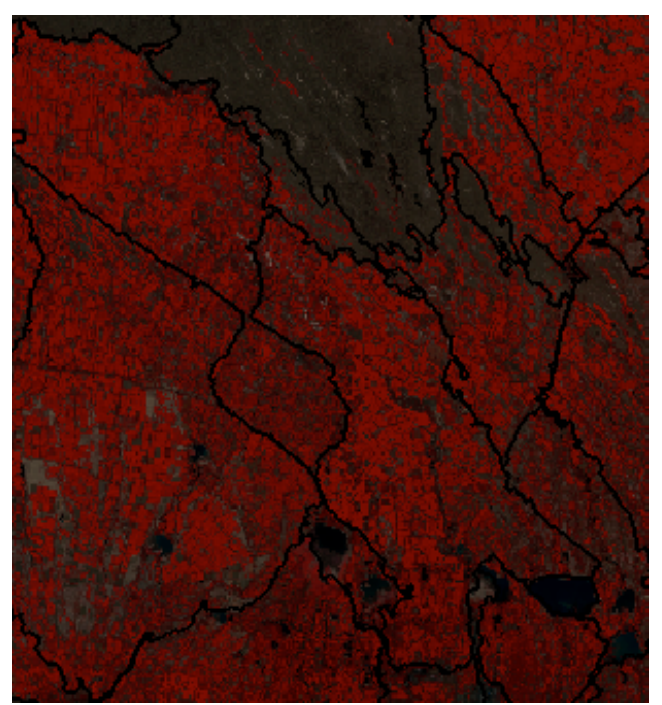

(a) Split dimension is 600

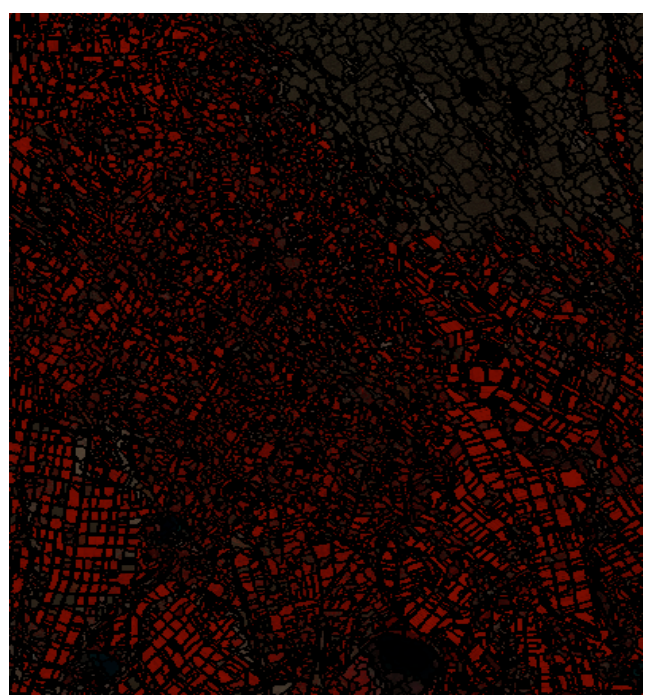

(b) Split dimension is 15

Figure 1. Area chart of the split process in different scales

\section{Extraction of all types of vegetation}

The various vegetation forms can be classified on the basis of NDVI value. The vegetation types include meadow, tillage, and forest land. We considered the NDSI value of the grassland to be between 0.11 and 0.4 . The NDSI value of the tillage is 0.4 . Healthy vegetation is sensitive to waveband 2 . Thus, we used this waveband to distinguish forestry, the slope and DEM data were used to establish a member function to decrease the error of vegetation.

\section{Extraction of other surface features}

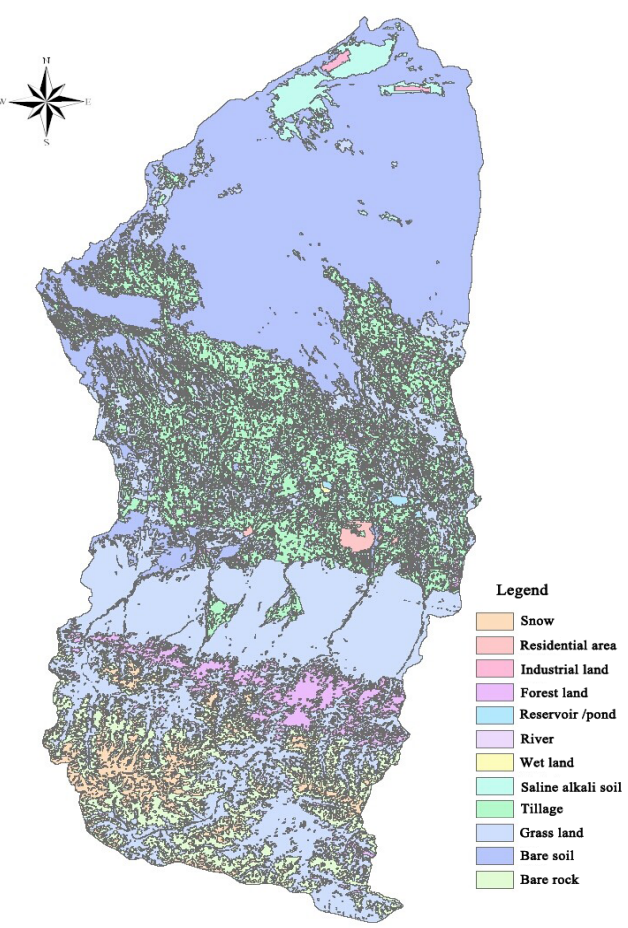

Figure 2. Land use classification results in Manasi River Basin

A significant difference was observed between the variance of band 1 within the housing estate and the other surface features. We find that the settlement area is dis- tributed along the two sides of the river and appears exhibits a Normal distribution. The industrial land is mainly distributed in the north, and its surface features can be extracted by using Google Earth and visual interpretation.

The saline in the RS image mainly appears as white and can be extracted by using visual interpretation. Bare soil and bare rock can be distinguished by DEM data. The classification results are shown in Figure 2 above.

Figure 2 shows that the vegetation within Manas River Basin exhibits certain regulation and that tillage has a regulation form. The grass land and the tillage exhibit a staggered distribution and are located in the central part of the oasis. The residential area is distributed along the two sides of the river and has a large amount of vegetation. The terrain appears to be high in the south but and low in the north. Thus, snow and forestry are mainly distributed in the south. The north is mainly composed of bare soil because of the drought in this area.

\section{RESUlTS AND ANALYSIS}

The area of the surface features can be calculated on the basis of the surface type and the resolution of the RS image. The formula used to calculate the area is described by Equations 1 and 2:

$$
\begin{aligned}
A_{i} & =N \cdot X \% \cdot 30^{2} \\
\text { Or } A_{i} & =N \cdot 30^{2}
\end{aligned}
$$

Where Ai represents the area of the different vegetation forms, $\mathrm{N}$ represents the pixel amount of the vegetation type, $\mathrm{X} \%$ represents the percentage between the different vegetation forms and the total pixel, 302 represents the area of each pixel (m2), and Ni represents the pixel number of the different vegetation types.

Based on the pixel amount on the classification map, the areas of the different vegetation types can be calculated by using the total vegetation area. The pixel number and the area of the different vegetation types are shown in table IV. Table IV shows that the vegetation in Manas River is abundant and accounts for a major part of the region. The bare soil and the bare rock areas can be exploited in the basin [13]. 


\section{PRECISION ANALYSIS}

\section{A. Evaluation methodology of precision analysis}

The error matrix is a standard format used to express the accuracy of RS image classification [14]. The error matrix is a matrix $(n \times n)$, where $N$ represents the amount of the type. The error matrix is shown in table $\mathrm{V}$.

Aimed at the error matrix of the RS image, the basic statistical magnitude includes:

1) Total classification accuracy is based on the correctly classified data divided by the total reference number [15], as shown in Equation (3):

$$
P_{c}=\sum_{k=1}^{n} P_{k k} / P
$$

2) Producer precision is given by the reference data divided by the correct classified data [13], as shown in Equation (4):

$$
P_{i j}=P_{i i} / P_{i+}
$$

3) User precision refers to the correctly classified data divided by the total data [13], as shown in Equation (5):

$$
P_{j i}=P_{i i} / P_{+j}
$$

4) Kappa index is a statistic value of the classification accuracy. The range is from 0 to 1 , as shown in Equation 6 [13]:

$$
K \frac{P \cdot \sum_{k=1}^{n} P_{k k}-\sum_{i=1}^{n} P_{+i} \cdot P_{i+}}{P^{2}-\sum_{i=1}^{n}\left(P_{+i} \cdot P_{i+}\right)}
$$

\begin{tabular}{|c|c|c|c|c|c|c|}
\hline Surface feature & Pixel & Area & & Surface feature & Pixel & Area \\
\hline Snow & 1246034 & 1121430600 & & Wet land & 23516 & 21164400 \\
\hline Resident land & 123050 & 110745000 & & Saline-alkali soil & 630096 & 567086400 \\
\hline Industrial land & 53537 & 48183300 & & Tillage & 6147194 & 5532474600 \\
\hline Forest land & 1674716 & 1507244400 & & Grass land & 12935064 & 11641557600 \\
\hline Reservoir & 88887 & 79998300 & & Bare soil & 11495660 & 10346094000 \\
\hline River & 56206 & 50585400 & & Bare soil & 2722338 & 2450104200 \\
\hline & & TABLE V. & & ROR MATRIX & & \\
\hline \multirow{2}{*}{\multicolumn{2}{|c|}{ Categorical data }} & \multicolumn{3}{|c|}{ Reference data } & \multirow{2}{*}{\multicolumn{2}{|c|}{ Line User precision Kappa }} \\
\hline & & 1 & $2 \ldots$ & $n$ & & \\
\hline \multicolumn{2}{|c|}{1} & P11 & $\ldots$ & Pn1 & \multicolumn{2}{|c|}{$\mathrm{P}+1$} \\
\hline \multicolumn{2}{|c|}{2} & $\mathrm{P} 22$ & $\cdots$ & $\cdots$ & \multicolumn{2}{|c|}{$\mathrm{P}+2$} \\
\hline \multicolumn{2}{|c|}{$\cdots$} & $\ldots$ & $\cdots$ & $\ldots$ & \multicolumn{2}{|c|}{$\ldots$} \\
\hline \multicolumn{2}{|c|}{$\mathrm{n}$} & & $\ldots$ & Pnn & \multicolumn{2}{|c|}{$\mathrm{P}+\mathrm{n}$} \\
\hline \multicolumn{2}{|c|}{ Total } & $\mathrm{P} 1+$ & $\mathrm{P} 2+$ & $\mathrm{Pn}+$ & \multicolumn{2}{|c|}{$\mathrm{P}$} \\
\hline \multicolumn{2}{|c|}{ Producer precision } & & & & & \\
\hline
\end{tabular}

\begin{tabular}{|c|c|c|c|c|c|c|c|c|c|c|c|c|c|}
\hline \multirow[b]{2}{*}{ Land cover } & \multicolumn{12}{|c|}{ Reference data } & \multirow[b]{2}{*}{ Total } \\
\hline & : & $\frac{\mathfrak{a}}{z}$ & $\begin{array}{c}7 \\
\vdots \\
0 \\
0\end{array}$ & $\frac{\Sigma}{\frac{1}{2}}$ & 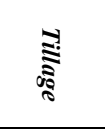 & ミ & $\begin{array}{l}\overrightarrow{0} \\
\stackrel{0}{8} \\
\stackrel{8}{8}\end{array}$ & 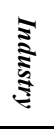 & $\stackrel{3}{3}$ & 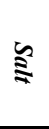 & 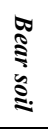 & 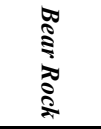 & \\
\hline River & 18 & 0 & 0 & 0 & 0 & 0 & 0 & 0 & 0 & 0 & 0 & 0 & 18 \\
\hline Snow & 0 & 46 & 0 & 0 & 0 & 0 & 0 & 0 & 0 & 0 & 0 & 0 & 0 \\
\hline Forest & 0 & 0 & 31 & 0 & 2 & 0 & 0 & 0 & 0 & 0 & 0 & 0 & 33 \\
\hline Wet land & 0 & 0 & 0 & 23 & 0 & 0 & 0 & 0 & 0 & 0 & 0 & 0 & 23 \\
\hline Tillage & 0 & 0 & 0 & 0 & 63 & 0 & 0 & 0 & 0 & 0 & 0 & 0 & 63 \\
\hline Grass Land & 0 & 0 & 0 & 0 & 0 & 104 & 1 & 0 & 0 & 0 & 0 & 8 & 113 \\
\hline Residence & 0 & 0 & 0 & 0 & 0 & 0 & 36 & 0 & 0 & 0 & 0 & 0 & 36 \\
\hline Industry & 0 & 0 & 0 & 0 & 0 & 0 & 0 & 79 & 0 & 0 & 0 & 0 & 79 \\
\hline Pond & 0 & 0 & 0 & 0 & 0 & 0 & 0 & 0 & 32 & 0 & 0 & 0 & 32 \\
\hline Salt & 0 & 0 & 0 & 0 & 0 & 0 & 0 & 0 & 0 & 71 & 0 & 0 & 71 \\
\hline Bear soil & 0 & 0 & 0 & 0 & 0 & 5 & 0 & 0 & 0 & 0 & 61 & 0 & 66 \\
\hline Bear Rock & 0 & 0 & 0 & 0 & 0 & 0 & 0 & 0 & 0 & 0 & 0 & 28 & 28 \\
\hline Total & 18 & 46 & 31 & 23 & 65 & 109 & 37 & 79 & 32 & 71 & 61 & 36 & \\
\hline Accuracy & 1 & 1 & 1 & 1 & $96.92 \%$ & $95.41 \%$ & $97.30 \%$ & 1 & 1 & 1 & 1 & $77.78 \%$ & \\
\hline
\end{tabular}

TABLE IV. PIXEL NUMBER AND AREA OF THE OBJECTS (UNIT: M2)

TABLE VI. PRECiSION EVALUATION OF THE TM IMAGE IN MANASI RiVER BASIN 


\section{B. Precision evaluation of TM image classification}

Random sampling based on object-oriented methods was conducted. Thematic map, field collected data, and the visual interpretation method were used to determine the truth-value of the research area, which was then employed as a basis to validate the classification results. The evaluation results are shown in Table VI.

Table VI shows that object-oriented technology is suitable for completing classification tasks.

\section{CONCLUSIONS:}

1) The producer precision, user precision, total classification accuracy, and total Kappa index reached high values. The total classification accuracy reached $97.37 \%$, whereas the total Kappa index was 0.9706.

2) Adding some distinctive land covers through manual modification can avoid interference and enhance the effectiveness of classification.

3) Object-oriented methods not only use spectral information on the surface features, but also fully consider the shape, texture, distribution, and the relationship of the surface features, thus preventing the metamerism phenomenon.

4) Object-oriented methods significantly enhance the efficiency and precision of classification.

\section{ACKNOWLEDGMENT}

Thanks to all the researchers during the process of publishing this paper.

\section{REFERENCES}

[1] Wang Fangju. "Fuzzy supervised classification of remote sensing images," IEEE Trans, On Geosci. and Remote Sensing, vol. 28(2) , pp.194-201, February 1990. http://dx.doi.org/10.1109/36.46698

[2] Benediktssn J A, Swain P H and Ersoy O K.'Neural network approaches versus statistical methods in classification of multisource remote sensing data".IEEE Trans.On Geosci. And Remote Sensing, vol. 28(4), pp. 540-552. April 1990. http://dx.doi.org/10.1109/TGRS.1990.572944

[3] Chen Zhong. "Research on high resolution remote sensing image classification technology".Beijing: Insititute of Remote Sensing Applications Chinese Academy of Sciences, 2006

[4] Chen Qiuxiao, Luo Jiancheng, Zhou Chenghu, et al. "Classification of remotely sensed imagery using multi-features based approach". Journal of Remote Sensing, vol. 8(3), pp. 239-245. March 2004.

[5] Yang Faxiang. "Some Problems on the Land Use and Degradation in Manas River Watershed, Xinjiang". Environmental Protection of Xinjiang, vol. 24(1), pp. 8-12. January 2002.

[6] Qin Yu, Peng Gong, et al.’Object-based detailed vegetation classification with airborne high spatial resolution remote sensing imagery".Photogrammetric Engineering and Remote Sensing, vol.
72(7), pp. 799-811. July 2006. http://dx.doi.org/10.14358/ PERS.72.7.799

[7] Volker Walter. "Object - based Classification of Remote Sensing Data for Change Detection," ISPRS Journal of Photogrammetry \& Remote Sensing, vol. 58, pp. 225-238. January 2004. http://dx.doi.org/10.1016/j.isprsjprs.2003.09.007

[8] Huang Huiping. "Scale Issues in Object-oriented Image Analysis." Beijing: Institute of Remote Sensing Applications Chinese Academy of Sciences, 2003

[9] Barlow J, Martin Y, Franklin S E. "Detecting Translational Landslide Scars Using Segmentation of Landsat ETM + and DEM Data in the Northern Cascade Mountains." British Columbia, Can J Remote Sensing. vol. 29(4) , pp. 510-517.April 2003. http://dx.doi.org/10.5589/m03-018

[10] Geneletti D $\square$ Gorte B G H. "A Method for Object- Oriented Land Cover Classification Combining Landsat TM Data and Aerial Photographs". Remote Sensing. vol. 24(6) , pp. 1273-1286. June 2003. http://dx.doi.org/10.1080/01431160210144499

[11] Ran Youhua, Li Wenjun, Chen Xianzhang. "Verification and assessment of land use classification by using TM image-taking Dingxi County as an example". Remote Sensing Technology and Application, vol. 18(2), pp. 81-86. February 2003.

[12] Haralick R M $\square$ Shanumgam K $\square$ Dinstein I. "Texture features for image classification". IEEE Trans.System Man Cybernet, vol. 3 (6), pp. 610-621. June 1973. http://dx.doi.org/10.1109/ TSMC.1973.4309314

[13] Yaojun Bo, Qingke Zhu, Weijun Zhao. "Optimal indicators for microtopography oriented soil quality assessment in semiarid regions of the loess plateau, China". INMATEH - Agricultural Engineering, vol. 42, pp. 105-114. January 2014.

[14] Li Jianhua, Wang Yiwen, Wang YiJun, Chen Yi; Wang, Guocheng. "Research on the Anti-Perspective Correction Algorithm of QR Barcode". Journal of Digital Information Management, Vol. 11, No. 3, pp. 202-206. June 2013

[15] He Lingyun, Meng Xianyong,et al. "Study on the Ecological Characteristics and Change Analysis of Xin Jiang Junggar Basin Based on the NDVI". Nature Environment and Pollution Technology, vol. 13(1), pp. 191-196. January 2014.

\section{AUTHORS}

Wang Ling is with the Geography Department of Shihezi University, Shihezi 832000 China (e-mail: rain_ling@163.com).

Su Jian-an is with the Geography Department of Shihezi University, Shihezi 832000 China (e-mail: rain_ling@163.com).

Guo Peng is with the Geography Department of Shihezi University, Shihezi 832000 China (e-mail: rain_ling@163.com).

This work was supported in part by The National Natural Science Foundation of China (41361073); Shihezi University high-level talents of high level scientific research start-up funding project (RCZX201130), Shihezi University (ZRKXYB-05) project). Submitted, July, 10, 2014. Published as resubmitted by the authors on October, 25, 2014. 